\title{
CONGENITAL DEFECTS OF THE TIBIA IN SIBLINGS WITH NEUROFIBROMATOSIS
}

\author{
J. M. WellwoOd, LONDON, and \\ J. H. Bulmer and D. J. C. GrafF, Wolverhampton, England \\ From the Royal Hospital, Wolverhampton
}

This paper reports congenital pseudarthrosis of the tibia in two brothers, both of whom have stigmata of neurofibromatosis. It is the first report in the English literature of pseudarthrosis of the tibia in siblings. The English mother suffers from neurofibromatosis with multiple café-au-lait spots; the father, a West Indian, has no evidence of neurofibromatosis or of skeletal deformity. A third child, a girl born in May 1968, has developed at least five café-au-lait spots of sufficient size to indicate a diagnosis of neurofibromatosis (Whitehouse 1966), but radiographs of both legs are normal. There is no history of neurofibromatosis or of pseudarthrosis in more distant members of the family.

\section{CASE REPORTS}

Case 1-Boy, born April 1965. This is the elder brother. He was born by normal delivery after uneventful pregnancy. His birth weight was 3.2 kilograms. At the age of seven months a collection of pigmented spots was noted on his back, and the lower third of the left leg was

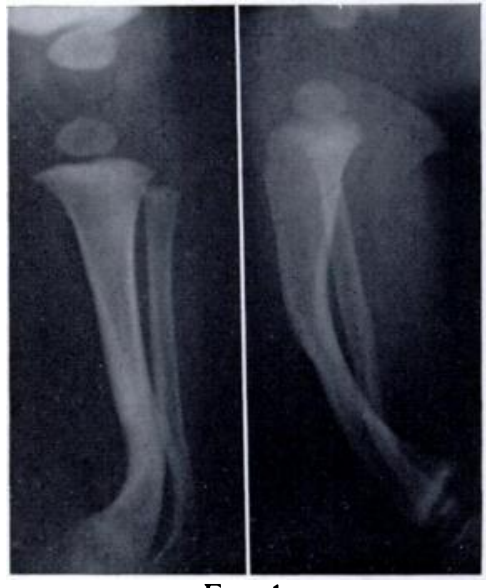

FIG. 1

FIGS. 1 AND 2

Case 1. Figure 1-The left tibia at age 7 months. Anterior bowing is present and the cortex thickened. The medullary cavity is present. Figure 2 -Fracture through bowed, sclerotic segment of left tibia at 20 months. A rarefied area is seen below the fracture. The fibula has also fractured.

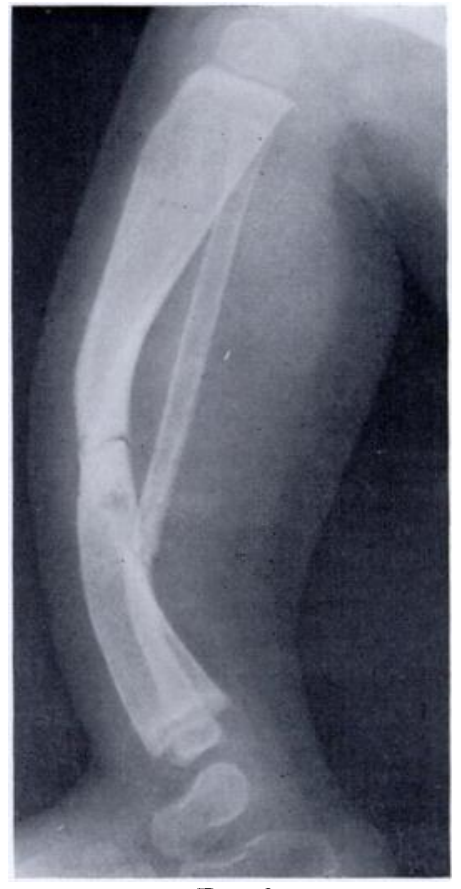

FIG. 2

seen to be curved. The mother had apparently noticed this bowing when the child was two weeks old. Radiographs showed anterior bowing of the tibia with cortical thickening which was most marked on the concave side. Though greatly attenuated at the site of angulation, a medullary cavity was present throughout (Fig. 1). The radiographic picture was that of 


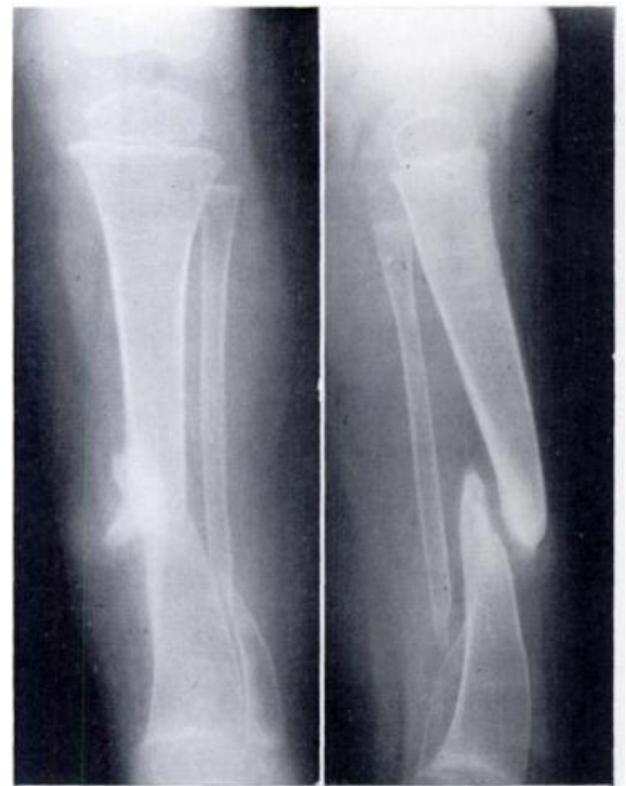

FIG. 3

FIGS. 3 AND 4

Case 1. Figure 3-Pseudarthrosis at 3 years. The bone ends are tapered and sclerosed. Figure $4-$ Age 5 years. The upper and lower ends of the graft appear to be incorporated, but the graft itself has fractured.

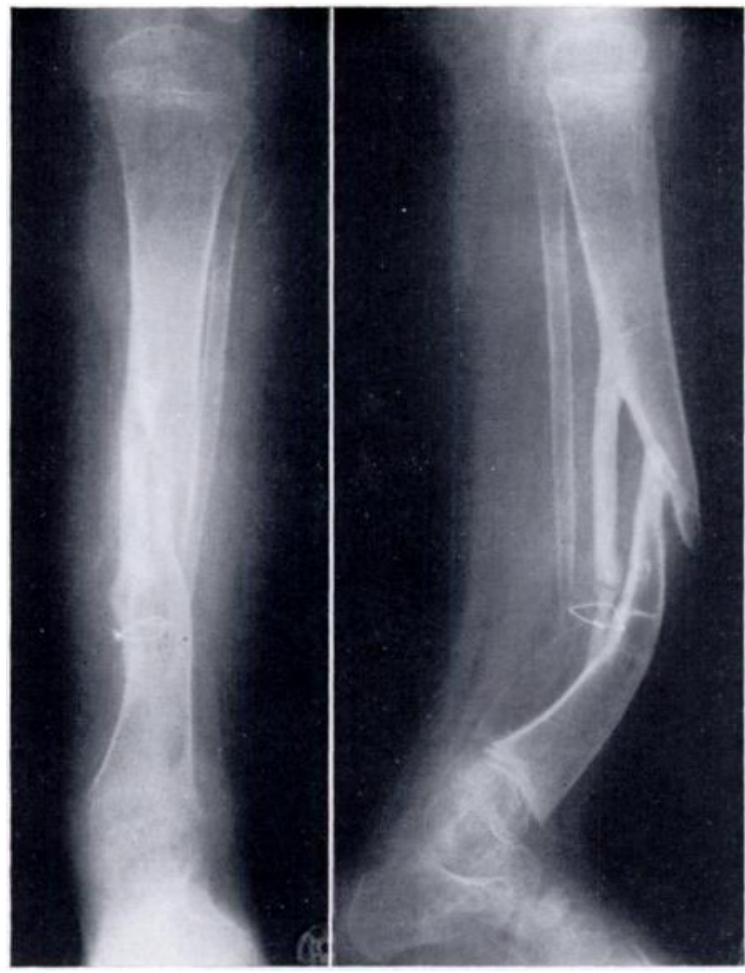

FIG. 4

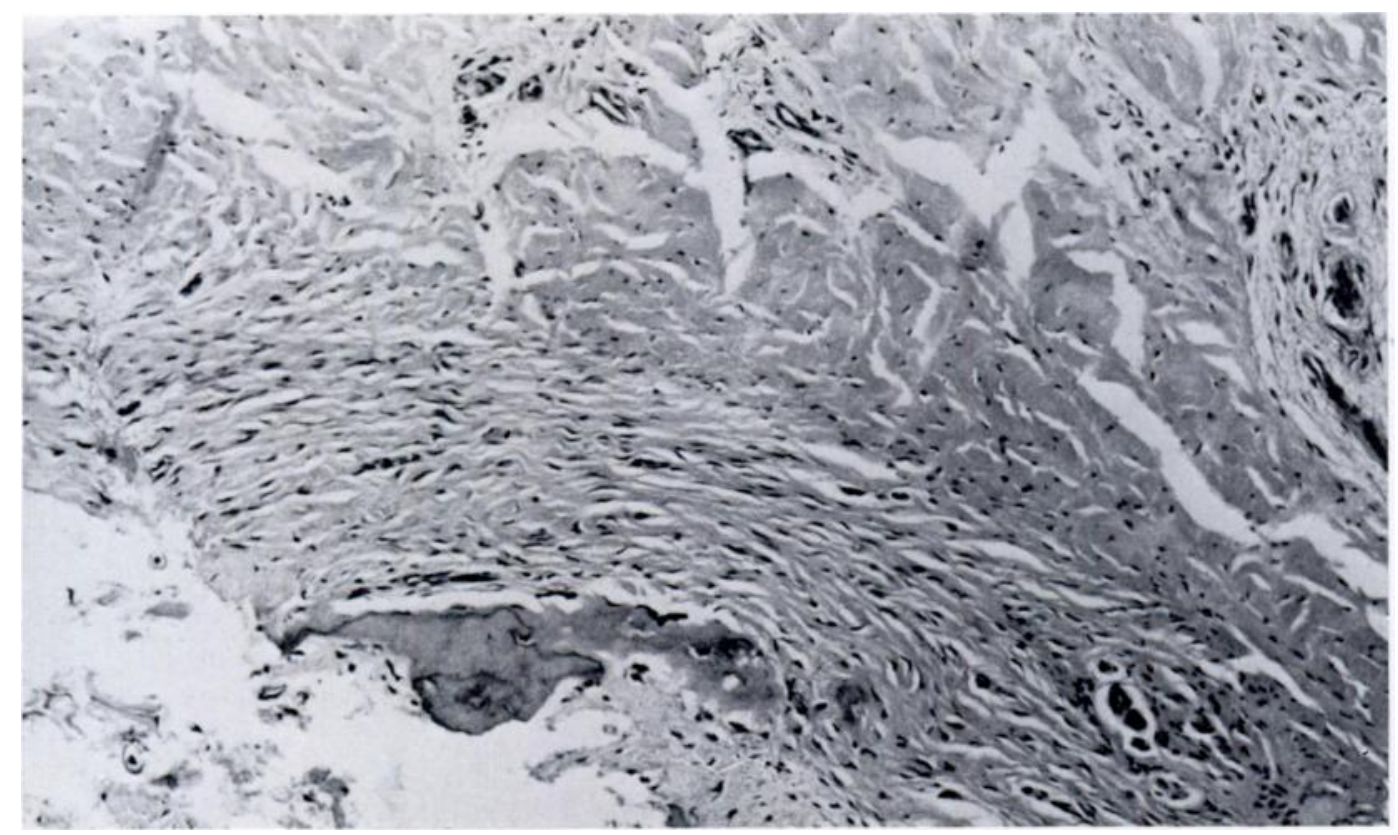

FIG. 5

Case 1-Low power view of biopsy specimen from pseudarthrosis of left tibia (see text). 
congenital kyphoscoliotic tibia (Badgley, O'Connor and Kudner 1952), and it was hoped that this deformity would correct spontaneously with growth. When the child was a year and a half old a lump was noticed in the left axilla, and a diagnosis of neurofibromatosis with café-au-lait spots was made. Two months later spontaneous fractures of the left tibia and fibula occurred through the area of deformity. A rarefied area was present in the shaft of the tibia just below the fracture (Fig. 2). A long-leg plaster was applied, but union did not occur and the bone ends became tapered and sclerosed (Fig. 3). The child was treated with a caliper and a plaster night splint without success until the age of three and a half years, when operation was undertaken. A delayed cortical graft from the right tibia was inserted into the left tibia in the manner of a "by-pass" graft, the ends of the graft being inserted into notches cut in the tibia above and below the pseudarthrosis. At the same time a biopsy specimen was obtained. The leg was immobilised in plaster and later in a long-leg caliper. In May 1970, at the age of five years, there was pain and mobility at the fracture site. Radiographs showed both ends of the graft to be incorporated in the tibia, but there was a fracture in the lower part of the graft (Fig. 4). The patient is now being treated in a long-leg plaster, and further operative measures may prove necessary. Figure 5 is a photomicrograph of the tissue removed from the pseudarthrosis. A sheaf of whorled fibrocytes is seen, with areas of osteoid tissue and bone below and to the left. Collagen is seen surrounding, and sharply demarcated from, the whorled fibrous tissue above and to the right.

Case 2-Boy, born November 1966 . The younger brother was also born by normal delivery after normal pregnancy. His birth weight was 3.7 kilograms. At birth he had a deformity of the left leg and radiographs showed a fracture of the tibia with tapering, sclerosed bone ends. A plaster splint was applied. Patches of brown pigment were noted on his back at the age of five weeks, and at the age of four months radiographs of the left tibia showed an upper and a lower pseudarthrosis on either side of a central area of sclerosed bone. Operative treatment was postponed because of the development and persistence of severe infantile eczema affecting particularly the left leg. Figure 6 is a radiograph taken at the age of six months. By twenty-two months there had been no improvement (Fig. 7), and since there was already 6.5 centimetres

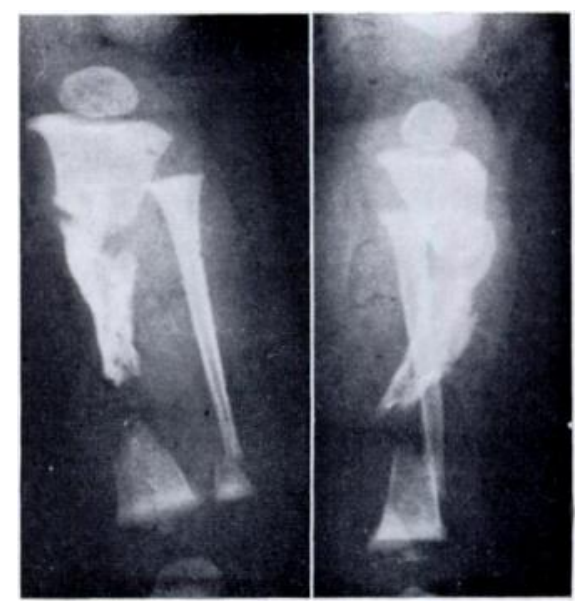

FIG. 6

FIGS. 6 AND 7

Case 2. Figure 6-"Double" pseudarthrosis of left leg at 6 months. Figure 7-Age 22 months: the middle segment of the left tibia had deteriorated.

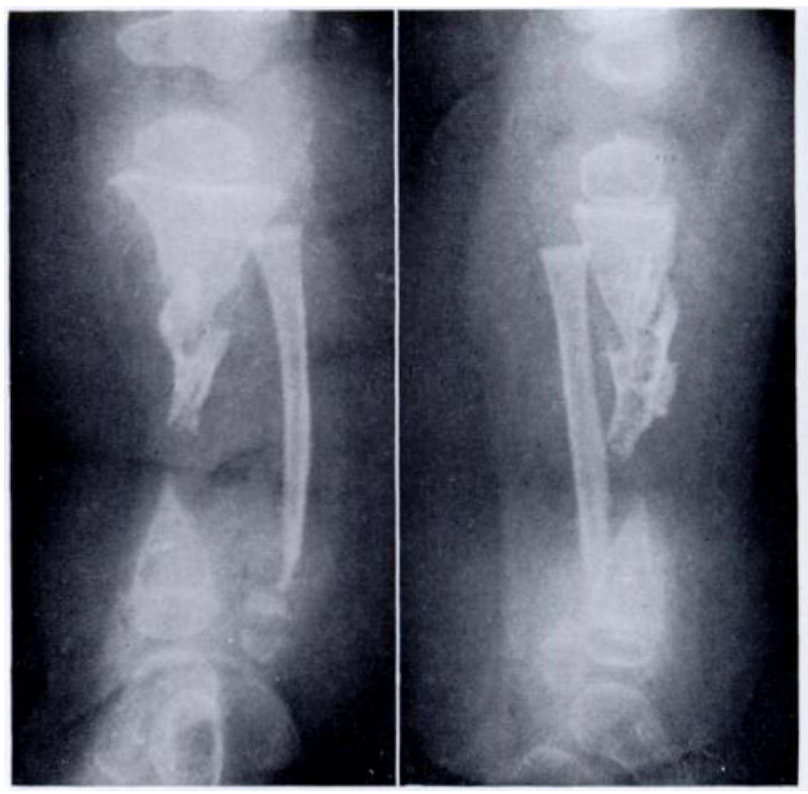

Fig. 7

THE JOURNAL OF BONE AND JOINT SURGERY 
of true shortening in the affected leg, and mobility at the fracture site had persisted (Fig. 8), amputation of the left leg was performed below the knee. The tibia in the region of the pseudarthrosis was invested with a thick sheath of fibrous tissue, and there was no bony continuity between the diaphysis and the proximal metaphysis of the tibia. When seen in May 1970 at the age of three and a half years, the patient was walking well with a prosthesis. Figure 9 is a photomicrograph of the area of the upper pseudarthrosis. The histological picture is similar to that of the pseudarthrosis in the elder brother. Whorls and sheaves of fibrocytes are seen with areas of osteoid tissue and bone to the left.

\section{DISCUSSION}

Congenital pseudarthrosis of the tibia is characterised by deossification, bending and pathological fracture, followed by the inability to form normal callus at the fracture site. The fibula may also be involved. The etiology is unknown, but congenital pseudarthrosis

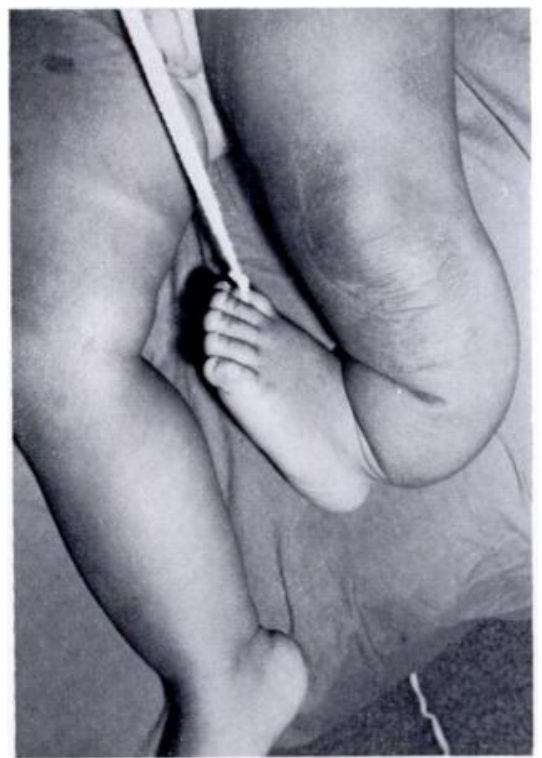

FIG. 8

Case 2-Photograph of the limb at age 22 months. There was free mobility at the site of pseudarthrosis. is frequently associated with stigmata of neurofibromatosis, particularly café-au-lait spots (Moore 1941, Green and Rudo 1943, Aegerter 1950, McCarroll 1950, Boyd and Sage 1958). Since neurofibromatosis is inherited as a dominant (Frank 1947, Fienman and Yakovac 1970), the rarity with which pseudarthrosis has occurred in more than one member of the family is noteworthy. Jacobs, Kimmelstiel and Thompson

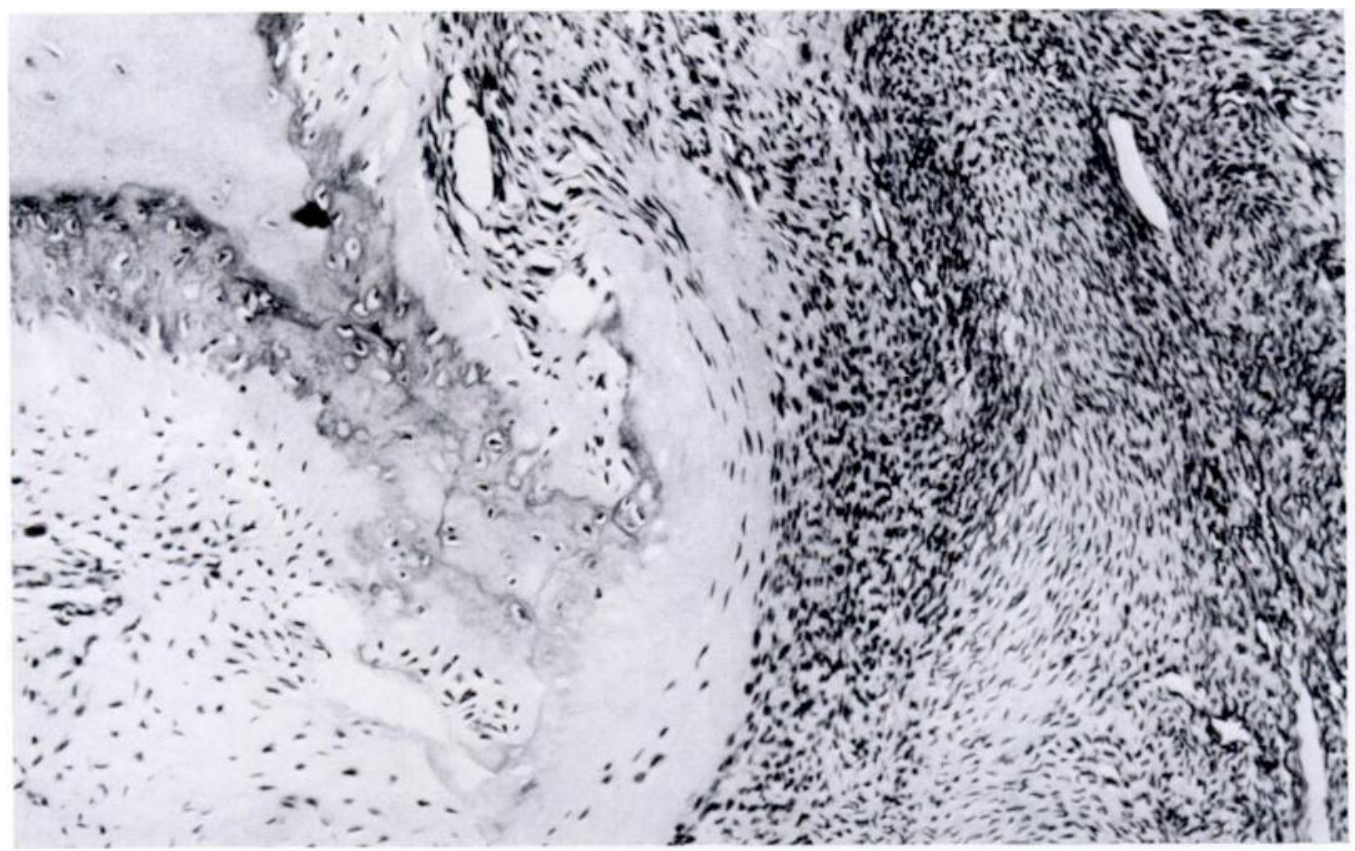

Fig. 9

Case 2-Low power view of a specimen from the pseudarthrosis (see text). 
(1949) described a patient with pseudarthrosis of the tibia whose maternal first cousin may have suffered from the same disease.

In view of the association between neurofibromatosis and pseudarthrosis, Moore (1941) believed that the neural abnormalities found in neurofibromatosis might cause defective bone development and result in pseudarthrosis. Badgley, O'Connor and Kudner (1952) suggested that pseudarthrosis of the tibia resulted from maldevelopment of the mesodermal structures in the leg during the fifth week of embryonic life caused by neurovascular abnormalities. Aegerter (1950) thought that the pseudarthrosis represented a hamartomatous proliferation of fibrous tissue. He pointed out that in addition to true tumours such as neurilemmomas and gliomas, hamartomatous proliferations are commonly found in neurofibromatosis, being evident in the bundle pattern of fibrocytes in plexiform nerve lesions and pedunculated skin tumours.

Another possible cause of pathological fracture and pseudarthrosis is the presence of intraosseous neurofibromatous masses. Green and Rudo (1943) reported such a case, and Jacobs, Kimmelstiel and Thompson (1949) noted "neurofibromatous tissue" within the pseudarthrosis. The histological appearance of pseudarthrosis in both our patients resembled that of neurofibroma, but could not be considered diagnostic. The nature of the rarefied area seen in the tibia of the elder brother (Fig. 2) is unknown. Other etiological factors that have been suggested include trauma to the foetus, metabolic, endocrine and nutritional abnormalities, and vascular lesions affecting bone.

Several clinico-pathological varieties of pseudarthrosis of the tibia have been described, which range from vicious to benign in behaviour (Boyd and Sage 1958, Nicoll 1969). In the more aggressive form of the disease, seen in the younger brother (Case 2), the thickened periosteum surrounding the tibia may reduce local blood supply and cause pressure atrophy of bone, leading to refracture and non-union (Boyd and Sage 1958). The elder brother (Case 1) presented with congenital bowing of the tibia. The cortex was thickened, the medullary cavity present and there was initially no fracture. This condition is said to run a more benign course and may regress with growth (Badgley, O'Connor and Kudner 1952; Aegerter and Kirkpatrick 1963). However, Lloyd-Roberts and Shaw (1969) stressed the danger of development of pseudarthrosis in patients with congenital anterior bowing of the tibia, and recommended prophylactic grafting.

The many methods of treatment that have been used for pseudarthrosis of the tibia include external splintage, a variety of techniques of bone grafting (McFarland 1940; Moore 1949; Boyd and Sage 1958; Eyre-Brook, Baily and Price 1969), intramedullary nailing (Charnley 1956), plating, and amputation. More than one operation is frequently required. The condition of pseudarthrosis tends to improve at skeletal maturity, although the results of treatment assessed after skeletal maturity have seldom been reported (Boyd and Sage 1958, Aegerter and Kirkpatrick 1963).

\section{SUMMARY}

The case histories of two brothers with congenital defects of the tibia and neurofibromatosis are presented. This report of congenital pseudarthrosis of the tibia in siblings is believed to be the first in the English literature.

We would like to thank Dr H. E. Everley-Jones and Dr A. G. Marshall for their help in the preparation of this paper, Mr R. Payton and his staff in the Photography Department for their help in preparing the illustrations and Miss Diana MacNair for her secretarial assistance.

\section{REFERENCES}

Aegerter, E. (1950): The Possible Relationship of Neurofibromatosis, Congenital Pseudarthrosis, and Fibrous Dysplasia. Journal of Bone and Joint Surgery, 32-A, 618.

Aegerter, E., and Kirkpatrick, J. A. (1963): Orthopedic Diseases. Second edition, p. 182. Philadelphia and London: W. B. Saunders Co. 
Badgley, C. E., O’Connor, S. J., and Kudner, D. F. (1952): Congenital Kyphoscoliotic Tibia. Journal of Bone and Joint Surgery, 34-A, 349.

Boyd, H. B., and SAge, F. P. (1958): Congenital Pseudarthrosis of the Tibia. Journal of Bone and Joint Surgery, 40-A, 1245.

Charnley, J. (1956): Congenital Pseudarthrosis of the Tibia Treated by the Intramedullary Nail. Journal of Bone and Joint Surgery, 38-A, 283.

Eyre-Brook, A. L., Baily, R. A. J., and Price, C. H. G. (1969): Infantile Pseudarthrosis of the Tibia. Journal of Bone and Joint Surgery, 51-B, 604.

Fienman, N. L., and Yakovac, W. C. (1970): Neurofibromatosis in Childhood. Journal of Pediatrics, 76, 339.

Frank, L. (1947): Von Recklinghausen's Disease Traced Through Five Generations. Archives of Dermatology and Syphilology, 55, 109.

Green, W. T., and Rudo, N. (1943): Pseudarthrosis and Neurofibromatosis. Archives of Surgery, 46, 639.

Jacobs, J. E., Kimmelstiel, P., and Thompson, K. R. (1949): Neurofibromatosis and Pseudarthrosis: Report of a Case. Archives of Surgery, 59, 232.

Lloyd-Roberts, G. C., and Shaw, N. E. (1969): The Prevention of Pseudarthrosis in Congenital Kyphosis of the Tibia. Journal of Bone and Joint Surgery, 51-B, 100.

McCarroll, H. R. (1950): Clinical Manifestations of Congenital Neurofibromatosis. Journal of Bone and Joint Surgery, 32-A, 601.

McFarland, B. (1940): 'Birth Fracture' of the Tibia. British Journal of Surgery, 27, 706.

MoORE, B. H. (1941): Some Orthopaedic Relationships of Neurofibromatosis. Journal of Bone and Joint Surgery, 23, 109.

Moore, J. R. (1949): Delayed Autogenous Bone Graft in the Treatment of Congenital Pseudarthrosis. Journal of Bone and Joint Surgery, 31-A, 23.

Nicoll, E. A. (1969): Infantile Pseudarthrosis of the Tibia. Journal of Bone and Joint Surgery, 51-B, 589.

Whitehouse, D. (1966): Diagnostic Value of the Café-au-lait Spot in Children. Archives of Disease in Childhood, 41, 316. 